\title{
Analogical effects in reading Dutch verb forms
}

\author{
MIRJAM ERNESTUS \\ Max Planck Institute for Psycholinguistics, Nijmegen, The Netherlands \\ and Radboud University Nijmegen, Nijmegen, The Netherlands \\ and \\ WILLEM MARINUS MAK \\ Utrecht University, Utrecht, The Netherlands \\ and Radboud University Nijmegen, Nijmegen, The Netherlands
}

\begin{abstract}
Previous research has shown that the production of morphologically complex words in isolation is affected by the properties of morphologically, phonologically, or semantically similar words stored in the mental lexicon. We report five experiments with Dutch speakers that show that reading an inflectional word form in its linguistic context is also affected by analogical sets of formally similar words. Using the self-paced reading technique, we show in Experiments 1-3 that an incorrectly spelled suffix delays readers less if the incorrect spelling is in line with the spelling of verbal suffixes in other inflectional forms of the same verb. In Experiments 4 and 5, our use of the self-paced reading technique shows that formally similar words with different stems affect the reading of incorrect suffixal allomorphs on a given stem. These intra- and interparadigmatic effects in reading may be due to online processes or to the storage of incorrect forms resulting from analogical effects in production.
\end{abstract}

Many studies have shown that the mental lexicon not only contains representations for morphologically simple words and for morphologically complex words with unpredictable characteristics, but also for completely regular morphologically complex words, including inflections (see, e.g., Alegre \& Gordon, 1999; Baayen, Dijkstra, \& Schreuder, 1997; Baayen, McQueen, Dijkstra, \& Schreuder, 2003; Bybee, 2000; Frisson \& Sandra, 2002; Sandra, Frisson, \& Daems, 1999; Stemberger \& MacWhinney, 1986, 1988). Other studies (e.g., Ernestus \& Baayen, 2003, 2004; Krott, 2001; Krott, Baayen, \& Schreuder, 2001; Skousen, 1989) have shown that these stored words and word forms may affect each other's production as well as the formation of new morphologically complex forms. For instance, Krott and colleagues (Krott, 2001; Krott et al., 2001) showed that the probability and the speed with which a speaker of Dutch chooses a given interfix for a new compound highly correlates with the frequency of the interfix among the existing compounds with the same initial constituent as the new compound. If the initial constituent is followed by a certain interfix in many existing compounds, speakers often choose this interfix, and when they do so, they react fast. Thus, the Dutch noun macht "power" is followed by the interfix $s$ in 71 out of 78 existing compounds (CELEX; Baayen, Piepenbrock, \& Gu-

We thank Harald Baayen, Dominiek Sandra, and Rob Schreuder for their comments on earlier versions of this article. Correspondence relating to this article may be sent to M. Ernestus, Max Planck Institute for Psycholinguistics, P.O. Box 310, 6500 AH Nijmegen, The Netherlands (e-mail: mirjam.ernestus@mpi.nl). likers, 1995), and most speakers of Dutch tend to create the new compound machtswoede out of macht "power" and woede "anger" by means of the interfix $s$. Moreover, when they do so, they are faster than when they choose to use another interfix or none at all. The studies on analogical effects have concentrated on the production of word forms in isolation. In the present study, we investigated whether analogical effects may also arise in comprehension, even when the words are presented in meaningful linguistic contexts.

During comprehension, language users may retrieve morphologically complex forms as complete units from the mental lexicon, or they may retrieve the morphemes of these words as separate units. The retrieval process may activate not only the forms themselves or their components, but also morphological, phonological, semantic, and orthographic neighbors, as has been shown, for instance, by Pisoni, Nusbaum, Luce, and Slowiaczek (1985) and Schreuder and Baayen (1997). It is not inconceivable that the coactivated neighbors affect comprehension, and therefore that analogical effects arise in word comprehension.

Analogical effects may arise in experimental settings especially when word forms are presented outside their linguistic contexts and participants are requested to react as fast as possible. If participants cannot prepare the word forms on the basis of the preceding linguistic context, but they nevertheless have to react quickly, they may take advantage of relations between word forms stored in their mental lexicon that they would not rely on under normal circumstances. In the present study, we investigated whether language users show analogical effects in comprehension even when the relevant word forms are 
Table 1

The Forms of Regular Dutch Verbs

\begin{tabular}{|c|c|c|}
\hline & $t$-Supporting Verbs & $d$-Supporting Verbs \\
\hline 1st-, 2nd-person singular present tense & stem & stem \\
\hline 2nd-, 3rd-person singular present tense & stem $+-t[\mathrm{t}]$ & stem $+-t[\mathrm{t}]$ \\
\hline Plural present tense, infinitive & stem + -en [ən] & stem + -en [ən] \\
\hline Singular simple past & stem $+-t e[\mathrm{t} ə]$ & stem $+-d e[\mathrm{~d} \partial]$ \\
\hline Plural simple past & stem + -ten $[\mathrm{t}$ ən] & stem + -den $[$ dən $]$ \\
\hline Present participle & stem + -end [ənt] & stem + -end [ənt] \\
\hline Inflected present participle & stem + -ende [əndə] & stem + -ende [əndə] \\
\hline Past participle & $g e-+$ stem $+-t[\mathrm{t}]$ & $g e-+$ stem $+-d[\mathrm{t}]$ \\
\hline Attributively used past participle & $g e-+$ stem $+-t e[\mathrm{t} \partial]$ & $g e-+$ stem $+-d e[\mathrm{~d} \partial]$ \\
\hline
\end{tabular}

presented in meaningful linguistic contexts and there is no time pressure.

Theoretically, the production or comprehension of a word form may be affected by words containing the same stem and by words containing other stems. For instance, the processing of a simple-past form may be affected by other forms in the same verb paradigm (e.g., the simple present of the same verb) and by the forms of other verbs. For this article, we studied both of these types of analogical effects, which we refer to as intraparadigmatic and interparadigmatic effects, respectively. That is, we addressed the question of whether the comprehension of one word is affected by other forms of the same word (intraparadigmatic analogy) and by the forms of other words (interparadigmatic analogy).

In this study, we focused on reading. Using the selfpaced reading paradigm, we presented words in meaningful linguistic contexts and measured reading times for these words and for the following words. Our test case was verb forms in Dutch.

In Table 1, we schematically present the orthographic and phonological forms of regular verb paradigms in Dutch. We distinguish two types of regular verbs: $t$-supporting and $d$-supporting verbs. The stems of $t$-supporting verbs end in unvoiced obstruents in the infinitive (in which the stem is followed by -en [ən]), and nearly all of their inflectional suffixes contain the grapheme $t$ and the sound [t]. The stems of $d$-supporting verbs, in contrast, end in all types of segments in the infinitive except for unvoiced obstruents. Some of their inflectional suffixes contain $d$ or [d], and only the third-person singular present tense suffix is spelled with a $t$. Note that the classification of obstruentfinal verb stems as $t$-supporting or $d$-supporting has to be based on the infinitive and cannot be based on forms in which the stem is word final or is followed by a consonantal suffix, since all obstruents in Dutch are unvoiced in syllable-final position (final devoicing) but voiced before voiced plosives (regressive voice assimilation).

The paradigms of the $t$-supporting verb krassen and the $d$-supporting verb lozen are given as examples in Table 2 . The phonological forms of lozen show that the spelling of the stem-final obstruent does not reflect its actual voice realization in all forms. Coda fricatives are always spelled as unvoiced, even when they are voiced as a result of regressive voice assimilation, as in loosde. In addition, coda stem-final plosives that are voiced before vowel-initial affixes are always spelled as voiced, even when they are unvoiced because of final devoicing (e.g., the first-person singular present tense of krabben [krabən] "to scratch" is spelled krab [krap]). Dutch also has completely irregular verbs with simple pasts and past participles that are not signaled by suffixes but by segmental changes in the verbal stem. For instance, the forms of the irregular verb wegen "to weigh" are weeg [vex], weegt [vext], wegen [veyən], woog [vox] (singular simple past), wogen [voyən] (plural simple past), wegend [veyənt], wegende [veyəndə], and gewogen [yəvoyən] (past participle). These irregular verbs are similar to $t$-verbs in that only the present participle contains a suffix with $d$.

In Experiments 1-3, we investigated the role of intraparadigmatic analogical effects in reading Dutch verb forms. We presented readers with third-person singular present tense forms embedded in sentences. The verb form was either spelled correctly with a $t$ (e.g., krast), or incorrectly with a $d$ (e.g., krasd). Incorrect $d$ is not supported by the inflectional forms of either $t$-supporting

Table 2

Two Examples: Krassen ("To Scrape") and Lozen ("To Drain")

\begin{tabular}{lll}
\hline & $t$-Supporting Verb & $d$-Supporting Verb \\
\hline 1st-, 2nd-person singular present tense & kras [kras] & loos [los] \\
2nd-, 3rd-person singular present tense & krast [krast] & loost [lost] \\
Plural present tense, infinitive & krassen [krasən] & lozen [lozən] \\
Singular simple past & kraste [krastə] & loosde [lozdə] \\
Plural simple past & krasten [krastən] & loosden [lozdən] \\
Present participle & krassend [krasənt] & lozend [lozənt] \\
Inflected present participle & krassende [krasəndə] & lozende [lozəndə] \\
Past participle & gekrast [yəkrast] & geloosd [yəlost] \\
Attributively used past participle & gekraste [yəkrastə] & geloosde [yəlozdə] \\
\hline
\end{tabular}


verbs or irregular verbs, since, except for the present participle, they do not contain suffixes with the sound [d] or the grapheme $d$. In contrast, incorrect $d$ does receive support from the inflectional forms of $d$-supporting verbs, since most inflectional forms contain $d$ or [d]. We therefore expected that if intraparadigmatic analogy affects reading, readers should have more problems with incorrect $d$ on the singular present tense forms of $t$-supporting verbs and irregular verbs than on $d$-supporting verbs.

In Experiments 4 and 5, we focused on interparadigmatic effects in reading. Our starting point for these experiments were studies by Ernestus and Baayen (2003, 2004) that documented the role of interparadigmatic effects in the production of simple past tenses in Dutch. According to the rule hypothesized in the phonological literature, and also according to orthographic conventions, simple pasts in Dutch are created by suffixing -te [tə] to verbal stems that end in unvoiced obstruents before infinitival -en or any other vowel-initial suffix ( $t$-supporting verbs) and by suffixing - $d e$ to all other stems ( $d$-supporting verbs). Notwithstanding this simple deterministic rule for simple past tense formation, Ernestus and Baayen (2003, 2004) showed that language users also base their choice between the two allomorphs on the stems that are phonologically similar to the relevant verb stem, henceforth referred to as the phonological neighbors. If the majority of the phonological neighbors end in unvoiced obstruents before vowel-initial suffixes, such as the infinitive suffix, speakers tend to add -te to new and existing stems. Conversely, if the majority of phonological neighbors end in voiced obstruents before vowel-initial suffixes, speakers tend to add $-d e$. Thus, according to the simple deterministic rule, the simple pasts for the verbs schrob [sxrop] "scrub" and zaag [zax] "saw" are created by adding -de to these stems, since the infinitives are schrobben [sxrobon], with a voiced [b], and zagen [zayən], with a voiced [y]. Nevertheless, speakers erroneously tend to add -te to schrob, because the majority of phonological neighbors, such as stop [stop] “stop," klop [klop] "knock," klap [klap] "clap," and sloep [slup] "sloop," end in unvoiced obstruents before vowel-initial suffixes. In contrast, speakers do not add -te to zaag, because the majority of phonological neighbors, including klaag [klax] "complain," daag [dax] "dawn," pleeg [plex] "commit," and traag [trax] "slow," end in voiced obstruents when followed word internally by vowels.

The relevant phonological neighbors are the stems ending in the same type of rhyme. As mentioned above, word-final obstruents are always realized as unvoiced; hence, the realization of a stem-final obstruent before a vowel-initial suffix, which determines the allomorph of the simple past tense suffix, does not follow from the realization of the stem in isolation. Ernestus and Baayen (2003) showed that the voicing of the stem-final obstruent before vowel-initial suffixes can be predicted to a certain extent, however, on the basis of the voice realization of the final obstruent of stems ending in the same type of rhyme. They built a classification tree (CART; based on Breiman, Friedman, Olshen, \& Stone, 1984) that grouped the final rhymes of 1,697 nouns, verbs, and adjectives ending in an obstruent into 11 gangs, such that rhymes with a similar preference for a voiced final obstruent before wordinternal vowels were grouped together. Table 3 presents the 11 analogical gangs, characterized by the final rhymes of their stems as realized in isolation. The segments enclosed by the first pair of brackets represent the possible vowels in the final rhymes of that gang, and the segments enclosed by the second pair of brackets represent the possible prefinal consonants, with a hyphen indicating the possible absence of a prefinal consonant. The final pair of brackets encloses the set of possible final obstruents, which are necessarily unvoiced when the stems are presented in isolation. Thus, the word schrob falls into gang 5, and zaag falls into gang 7. Table 3 also lists the proportion of stems in each gang that have voiced final obstruents before vowel-initial suffixes, which represents the gang's analogical support for final voicing. The gangs differ in their support for voicing, thus showing that the

Table 3

Analogical Gangs, Defined in Terms of Segments of the Final Rhymes of Verb Stems in Isolation, and Their Support for Voiced Obstruents Before Vowel-Initial Suffixes (From Ernestus \& Baayen, 2003)

\begin{tabular}{|c|c|}
\hline Analogical Neighborhood Gangs & Support for Voicing \\
\hline 1. $\{\varepsilon i, a u, œ y, a:, e:, o:,:, i, u\}\{-, j, 1, m, n, r\}\{p\}$ & .000 \\
\hline 2. $\{c i, a u, œ y, a:, e:, o: \varnothing:, i, u\}\{-, j, 1, m, n, r\}\{t\}$ & .372 \\
\hline 3. $\{\varepsilon i, a u, œ y, a:, e:, o:, \varnothing ;, \mathrm{i}, \mathrm{u}\}\{-, \mathrm{j}, \mathrm{l}, \mathrm{m}, \mathrm{n}, \mathrm{r}\}\{\mathrm{s}\}$ & .755 \\
\hline 4. $\{\varepsilon i, \mathrm{au}, œ y, \mathrm{a}:, \mathrm{e}, \mathrm{o}:,: \mathrm{i}, \mathrm{u}, \mathrm{a}, \varepsilon, \mathrm{I}, \supset, \mathrm{y}, \mathrm{y}\}\{\mathrm{f}, \mathrm{k}, \mathrm{p}, \mathrm{s}, \mathrm{t}, \mathrm{x}\}\{\mathrm{p}, \mathrm{t}, \mathrm{s}\}$ & .019 \\
\hline 5. $\{\mathrm{a}, \varepsilon, \mathrm{I}, \rho, \mathrm{y}, \mathrm{y}\}\{-, \mathrm{m}, \mathrm{r}\}\{\mathrm{p}, \mathrm{t}, \mathrm{s}\}$ & .135 \\
\hline 6. $\{\mathrm{a}, \varepsilon, \mathrm{I}, \supset, \mathrm{Y}, \mathrm{y}\}\{1, \mathrm{n}\}\{\mathrm{p}, \mathrm{t}, \mathrm{s}\}$ & .357 \\
\hline 7. $\{\varepsilon i, a u, a:, e:, o:,:, y\}\{-, j, 1, m, n, r\}\{f, x\}$ & .992 \\
\hline 8. $\{\mathrm{i}, \mathrm{u}\}\{-, \mathrm{m}\}\{\mathrm{f}\}$ & .778 \\
\hline 9. $\{\mathrm{a}, \varepsilon, \mathrm{I}, \supset, \mathrm{Y}\}\{-, \mathrm{m}\}\{\mathrm{f}\}$ & .081 \\
\hline 10. $\{\mathrm{a}, \varepsilon, \mathrm{I}, \supset, \mathrm{y}, \mathrm{i}, \mathrm{u}\}\{1, \mathrm{r}\}\{\mathrm{f}\}$ & .775 \\
\hline 11. $\{\mathrm{a}, \varepsilon, \mathrm{I}, \mathrm{\jmath}, \mathrm{Y}, \mathrm{i}, \mathrm{u}\}\{-, \mathrm{j}, \mathrm{l}, \mathrm{r}, \mathrm{m}, \mathrm{n}\}\{\mathrm{x}\}$ & .953 \\
\hline
\end{tabular}

Note-The segments between the first pair of brackets present the possible vowels of the final rhymes, and the segments between the second pair indicate potential prefinal consonants. (A "-" represents the possible absence of a prefinal consonant.) The final pair of brackets encloses potential final obstruents. 
realization of a stem-final obstruent before vowel-initial suffixes can be predicted to some extent on the basis of the relevant gang.

Speakers take advantage of this predictability. A gang's support for voicing correlates with the proportion of participants adding -de to pseudowords falling in that gang (Ernestus \& Baayen, 2003), and it accounts for the incorrect simple-past forms that speakers produce-that is, the forms with a simple-past allomorph that violates the generative phonological rule and the Dutch spelling conventions (Ernestus \& Baayen, 2004). Speakers tend to select the simple-past allomorph that is supported by the voicing preference of the phonological gang of the verb, irrespective of whether this allomorph is in line with the realization of the stem-final obstruent of the verb itself before vowel-initial suffixes. Moreover, speakers select the incorrect allomorph more often if the analogical support for this allomorph is greater.

In our study, we investigated readers' reactions to incorrect allomorphs. We expected that incorrect allomorphs would delay reading. However, given the production data, we also expected that readers would be delayed less when an incorrect allomorph was supported by the analogical gang of the verb than when it was not. This pattern would form evidence for interparadigmatic analogy in reading, since it would show that different words - thus, words belonging to different paradigms - affect each other.

We now turn to Experiment 1, which focuses on intraparadigmatic effects on reading present tense verb forms. In this experiment, we investigated whether an incorrect spelling of the third-person present tense suffix as $-d$ instead of - $t$ delays readers less if a verb is $d$ supporting rather than $t$ supporting.

\section{EXPERIMENT 1}

\section{Method}

Participants. Sixty-two participants, mostly undergraduates at Radboud University Nijmegen, were paid to take part in the experiment. All were native speakers of Dutch.

Materials and Design. We selected the third-person singular present tense forms of eight monomorphemic $t$-supporting verbs and eight monomorphemic $d$-supporting verbs (see the Appendix). The forms were matched for length [on average, 4.38 and 4.63 graphemes, respectively; $t(14)=-0.78, p>.10]$ and for the log of their frequency in the Dutch section of the CELEX lexical database, which is based on a corpus of 42 million words [on average, 2.44 and 2.36, respectively; $t(14)=0.10, p>.10]$. The forms were embedded in sentences, as illustrated in Example 1 below. Each sentence consisted of a subject noun phrase, the verb form, an (object) noun phrase, and a prepositional phrase. Some sentences continued after the prepositional phrase. Each verb form was spelled correctly in one version of the sentence and misspelled with a $d$ instead of a $t$ in another version of the sentence. Apart from the final grapheme of the verb form, the two versions of a sentence were identical (compare Examples 1A and 1B).

(1A) Het schip loost zijn olie bij de haveningang.

(1B) Het schip loosd zijn olie bij de haveningang. The ship drains its oil at the harbor entrance. "The ship is draining its oil at the entrance of the harbor."
Since each sentence had two versions, we had a total of 32 experimental sentences. They were divided into two experimental lists so that each list contained one version of every sentence, including 4 experimental sentences with misspelled $d$-supporting verb forms and 4 with misspelled $t$-supporting verb forms. In addition, the two lists contained 80 filler sentences with 24 incorrectly spelled nouns and 8 incorrectly spelled verbs. The nouns were misspelled with respect to the manner or place of articulation of the first grapheme, and the 8 verb forms were misspelled with the suffix $-d$ instead of - $t$ (as were the misspelled experimental verbs). In total, 32 of the 96 sentences presented to a participant contained a misspelling. The experimental sentences and the filler sentences were pseudorandomly mixed so that both the correctly and incorrectly spelled $t$-supporting verbs and both the correctly and incorrectly spelled $d$ supporting verbs were evenly distributed over the lists. The order of the sentences was identical in the two lists.

Every sentence in the experiment was followed by a question. These questions stimulated the participants to read the sentences carefully and to focus on content instead of form. The question that followed the sentences in Example 1 is presented in Example 2.

(2) Is de schipper zeer begaan met het milieu?

"Does the captain feel much compassion for the environment?"

Before the experiment started, the participants were presented with a practice block of 14 sentences. These practice sentences were similar to the ones in the experiment and were also followed by questions. They did not contain misspelled words.

Procedure. The participants performed a self-paced reading task. They were tested individually, sitting in a dimly lit room in front of a PC monitor and a panel with three buttons. The course of a trial was as follows: The participant saw a fixation point, indicating the starting position of all sentences. The participant then pressed the middle button, and a complete sentence was presented on the screen. The letters, however, were replaced by dashes. Only the full stop at the end of the sentence was visible. The participant pressed the middle button, and the dashes of the first word were converted into letters. The participant read this word and pressed the middle button again, which reconverted the letters of the first word into dashes, and made the second word legible. The participant read this word, pressed the button, and read the following word. This was repeated until the participant had read all words of the sentence. The participant then saw the word vraag "question" for $1.0 \mathrm{sec}$ on the screen, followed by the question about the sentence. If the answer to the question was yes, the participant pressed the right button. If the answer was no, the participant pressed the left button. We measured the time span between the successive buttonpresses - that is, the time a participant needed to read each word in the sentence. In addition, we also registered the responses to the questions.

Half of the participants read the sentences of one list, the other half read the sentences of the other list. In the instructions, the participants were told that some sentences contained misspellings, which they should ignore, and that it would be clear which word was intended.

\section{Results}

We excluded 2 participants from the data set because they answered more than $10 \%$ of the questions incorrectly. The remaining participants on average answered $4 \%$ of the questions incorrectly. From their trials, we discarded extremely long ( $>4,000 \mathrm{msec})$ and extremely short $(<50 \mathrm{msec})$ reading times. In addition, we excluded reading times that were more than two standard deviations away from both the participant and item means for a given position in a given condition. In total, we excluded 33 trials performed by the remaining participants $(1.7 \%)$. 
Table 4

\begin{tabular}{|c|c|c|c|c|}
\hline \multicolumn{5}{|c|}{$\begin{array}{c}\text { Average Reading Times (in Milliseconds) for the Third-Person Singular } \\
\text { Present Tense Verb Forms With Correct } t \text { or Incorrect } d \text { and for the } \\
\text { Two Directly Following Words in Experiment } 1\end{array}$} \\
\hline & & Form & Word & Word \\
\hline \multirow[t]{3}{*}{$d$-supporting verbs } & correct $t$ & 371 & 357 & 372 \\
\hline & incorrect $d$ & 383 & 385 & 371 \\
\hline & incorrect - correct & 12 & 28 & 1 \\
\hline \multirow[t]{3}{*}{$t$-supporting verbs } & correct $t$ & 387 & 365 & 374 \\
\hline & incorrect $d$ & 446 & 398 & 381 \\
\hline & incorrect - correct & 59 & 33 & 7 \\
\hline
\end{tabular}

We analyzed the reading times from this experiment and from the following experiments not only for the target word but also for the following words, since there is often a spill-over effect to the following words in self-paced reading experiments (Just, Carpenter, \& Woolley, 1982). Furthermore, we included reading speed in the analyses of the experiments, since it was possible that only slow readers would notice the misspellings. Slow readers may pay more attention to the exact spelling of words, and they may therefore notice spelling errors that are missed by fast readers. Some participants may have been slow because they noticed the misspellings from the very beginning of the experiment and read more carefully from that point onward. In addition, it is also possible that fast readers could show more spill-over effects than do slow readers. We determined a participant's reading speed on the basis of the reading times for all of the experimental sentences after data exclusion.

Table 4 shows the average reading times for the verb forms that were correctly spelled with a $t$, the verb forms incorrectly spelled with a $d$, and for the two words immediately following these verb forms. The table distinguishes between the $d$-supporting verbs and the $t$-supporting verbs. We analyzed the data by means of two analyses of variance, one with participants $\left(F_{1}\right)$ and one with items $\left(F_{2}\right)$ as the random variable. The factors in the analyses were verb type ( $d$-supporting vs. $t$-supporting), correctness (correctly spelled vs. misspelled), position (the verb form itself vs. the following word), and reading speed (the 30 fastest vs. the 30 slowest participants). We only took the reading times for the verb form and the directly following word into account, since Table 4 shows that the reading times for the second following word are hardly affected by the spelling of the verb form. If there are intraparadigmatic effects on reading, we would expect an interaction of correctness and verb type, showing that readers are less delayed by an incorrect $d$ if the paradigm of the verb is $d$-supporting.

Both the participant and the item analyses showed main effects of correctness $\left[F_{1}(1,58)=27.84, p<.01\right.$; $\left.F_{2}(1,14)=13.54, p<.01\right]$, position $\left[F_{1}(1,58)=3.90\right.$, $\left.p=.05 ; F_{2}(1,14)=9.50, p<.01\right]$, and speed $\left[F_{1}(1,58)=\right.$ $\left.90.52, p<.01 ; F_{2}(1,14)=261.71, p<.01\right]$ and interactions of correctness and reading speed $\left[F_{1}(1,58)=12.23\right.$, $\left.p<.01 ; F_{2}(1,14)=6.73, p=.02\right]$ and position and read- ing speed $\left[F_{1}(1,58)=11.07, p<.01 ; F_{2}(1,14)=22.40\right.$, $p<.01]$. The fast participants read faster than the slow participants, and they all read faster when the verb form was spelled correctly. However, incorrect spellings delayed the fast readers by only $11 \mathrm{msec}$ (their average reading time in the correct condition was $286 \mathrm{msec}$, and in the incorrect condition, $297 \mathrm{msec})$, but they delayed the slow readers by $55 \mathrm{msec}$ (correct condition, $454 \mathrm{msec}$; incorrect condition, $509 \mathrm{msec}$ ). The effect of correctness for the fast readers was only significant in the participant analysis $\left[F_{1}(1,29)=4.41, p=.05 ; F_{2}(1,14)=1.44, p>\right.$ $.10]$, whereas it was significant in both the participant and the item analyses for the slow readers $\left[F_{1}(1,29)=\right.$ $\left.23.45, p<.01 ; F_{2}(1,14)=13.77, p<.01\right]$. The fast and slow readers also differed in how fast they read the verb forms in comparison with the following function words. Whereas the fast readers read the two words on average equally fast (284 msec and $298 \mathrm{msec}$ for the two words, respectively), the slow readers needed more time to read the verb form (on average, $508 \mathrm{msec}$ ) than to read the function word (454 msec).

The participant analysis also showed a main effect of verb type $\left[F_{1}(1,58)=7.48, p<.01 ; F_{2}(1,14)=1.04\right.$, $p>.10]$, the hypothesized interaction of correctness and verb type $\left[F_{1}(1,58)=3.86, p=.05 ; F_{2}(1,14)=1.29\right.$, $p>.10]$, and an interaction of verb type and position $\left[F_{1}(1,58)=4.00, p=.05 ; F_{2}(1,14)=3.33, p=.09\right]$, as well as a three-way interaction of correctness, verb type, and position $\left[F_{1}(1,58)=4.17, p=.05 ; F_{2}(1,14)=3.24\right.$, $p=.09]$. Since there were only eight verbs of each type and correctness was counterbalanced over two participant groups, it is not surprising that the interactions with correctness did not reach significance in the item analysis.

We studied the three-way interaction in more detail by investigating whether both the reading times for the verb forms and for the following words showed an interaction of verb type and correctness, which was the main focus of our study. The reading times at the verb forms showed the interaction $\left[F_{1}(1,58)=5.66, p=.02 ; F_{2}(1,14)=4.12\right.$, $p=.06]$; correctness was significant for the $t$-supporting verbs $\left[F_{1}(1,58)=12.12, p<.01 ; F_{2}(1,7)=17.80\right.$, $p<.01]$, whereas it was not for the $d$-supporting verbs $\left[F_{1}(1,58)=0.77, p>.10 ; F_{2}(1,7)=0.56, p>.10\right]$. The main effect of correctness was significant $\left[F_{1}(1,58)=\right.$ $\left.13.09, p<.01 ; F_{2}(1,14)=7.42, p=.02\right]$, but there was 
no interaction of correctness with verb type at the position of the following word (both $F \mathrm{~s}<1$ ). We see that if the verbal paradigm does not support $d$, incorrect $d$ delays the reading of the verb form itself and of the following word. In contrast, if the verb form supports $d$, incorrect $d$ delays reading times only at the word following the verb, not at the verb itself.

\section{Discussion}

The experimental results suggest that readers have more problems with an incorrect $d$ if the inflectional paradigm of the verb does not support $d$. This effect of verb type is in line with our hypothesis of intraparadigmatic effects in reading. An alternative explanation of the attested effect is possible, however. The final grapheme sequences of the $d$-supporting verb stems are regularly followed by word-final $d$, whereas the final grapheme sequences of the $t$-supporting verb stems never are (see Table 5 , which gives the grapheme sequences at the ends of the verb stems in the experiment and the frequencies with which these sequences are followed by word-final $t$ and wordfinal $d$ according to CELEX). Readers are familiar with the grapheme sequences in the misspelled $d$-supporting verb forms, whereas they are not with the grapheme sequences in the misspelled $t$-supporting verb forms. Our results, therefore, do not necessarily form evidence for intraparadigmatic effects; they may show the effects of the frequencies of the grapheme sequences in the two types of misspelled forms.

We designed Experiment 2 to test whether there is also a difference between verbs that do and do not support $d$, if their final grapheme sequences are equally often followed by $d$. In this experiment, we compared $d$-supporting verbs with completely irregular verbs. The inflectional forms of completely irregular verbs are neutral to the orthographic form of the third-person singular present tense, since they do not take suffixes with [d], [t], $d$, or $t$, apart from the present participle, which is spelled with $d$ and pronounced with [d] or [t], depending on the presence or absence of the inflectional schwa. In the following discussion, we will therefore refer to these completely irregular verbs as neutral verbs. We selected $d$-supporting verbs and neutral verbs that end in the same types of graphemes in the infinitive so that their stem-final grapheme sequences are

Table 5

Frequencies With Which the Final Rhymes of the $d$-Supporting Verbs and the $t$-Supporting Verbs in Experiment 1 Are Followed by Word-Final $\boldsymbol{t}$ and $\boldsymbol{d}$,According to CELEX

\begin{tabular}{llrr}
\hline \multirow{2}{*}{ Verb Type } & Grapheme Sequence & $\begin{array}{c}\text { Frequency } \\
\text { With } t\end{array}$ & $\begin{array}{r}\text { Frequency } \\
\text { With } d\end{array}$ \\
\hline$d$-supporting verbs & long vowel $+g$ & 27,182 & 22,717 \\
& short vowel $+g$ & 36,577 & 37,393 \\
& long vowel $+s$ & 141,293 & 6,404 \\
& $n s$ & 23,996 & 427 \\
$t$-supporting verbs & $r f$ & 1,929 & 775 \\
& short vowel $+p$ & 12,763 & 0 \\
& $m p$ & 1,736 & 0 \\
& short vowel $+s$ & 91,403 & 0 \\
\hline
\end{tabular}

approximately equally often followed by $d$ as well as by $t$. We hypothesize that if the within-paradigm neighbors affect the reading of a misspelled verb form, the spelling of a present tense form with $d$ should cause fewer problems with the $d$-supporting verbs than with the neutral verbs.

\section{EXPERIMENT 2}

\section{Method}

Participants. Forty native speakers of Dutch were paid for their participation. They were undergraduate students at Radboud University Nijmegen and had not participated in Experiment 1.

Materials and Design. We selected 20 pairs of monomorphemic stems, each consisting of a $d$-supporting stem and a neutral stem (see the Appendix). The stems of each pair ended in exactly the same obstruent, both in isolation and in the infinitive, and in the majority of cases this obstruent was preceded by a vowel of the same phonological length (long or short). Thus, the final grapheme sequences of the two stems of a pair were approximately equally often followed by $d$ or by $t$ (see Table 3). For instance, we formed the pair pleeg-weeg. The verb pleeg "commit" is a $d$-supporting verb, and weeg "weigh," with woog [vox] as its simple past and gewogen [уәขоуən] as its past participle, is a neutral verb.

The third-person singular present tense forms of the selected $d$ supporting and neutral verbs were of approximately the same length [on average, 5.40 and 5.45 graphemes, respectively; $t(38)=-1.24$, $p>.10$ ] and $\log$ frequency [on average, 4.58 and 4.53 , respectively; $t(38)=0.10, p>.10]$. The verb forms were embedded in sentences of the same structure as the sentences in Experiment 1. Each sentence was followed by a question.

We constructed two experimental lists in such a way that experimental items spelled incorrectly in one list were spelled correctly in the other list, and vice versa. Both lists contained 10 misspelled forms of $d$-supporting verbs and 10 misspelled forms of neutral verbs. In each list, the 40 experimental sentences were pseudorandomly mixed with 100 filler sentences, some of which contained nouns in which the first grapheme was incorrect. In total, 54 of the 140 sentences in a list contained a misspelling. Each list was preceded by 14 practice sentences. The order of the sentences was the same in the two lists.

Procedure. The procedure was the same as in Experiment 1.

\section{Results}

We excluded 1 participant from the data set, since this participant answered less than $90 \%$ of the questions correctly. We also excluded 3 other participants because of excessively long reading times (overall mean $>600 \mathrm{msec}$ ). Finally, we excluded 53 reading times $(1.2 \%$ of the remaining reading times) that were more than two standard deviations away from both the participant and item means for a given position in a given condition. Table 6 shows the average reading times for the correctly and incorrectly spelled verb forms and the two following words. We analyzed the reading times by means of participant and item analyses of variance, with verb type ( $d$-supporting vs. neutral), correctness (correctly spelled vs. misspelled), position (the verb form itself vs. the following word), and reading speed (the 18 fastest vs. the 18 slowest participants) as the independent variables. We only considered the reading times for the verb form itself and the directly following word, since the spelling of the verb form hardly affected reading times for the second following word (see Table 6). 
Table 6

Average Reading Times (in Milliseconds) for Third-Person Singular Present Tense Forms Correctly Spelled With $t$ or Incorrectly Spelled With $\boldsymbol{d}$ and for the Two Directly Following Words in Experiment 2

\begin{tabular}{llrrr}
\hline & & $\begin{array}{c}\text { Verb } \\
\text { Form }\end{array}$ & $\begin{array}{r}\text { Following } \\
\text { Word }\end{array}$ & $\begin{array}{c}\text { 2nd Following } \\
\text { Word }\end{array}$ \\
\hline$d$-supporting verbs & correct $t$ & 326 & 324 & 320 \\
& incorrect $d$ & 338 & 326 & 326 \\
Neutral verbs & incorrect - correct & 12 & 2 & 6 \\
& correct $t$ & 331 & 315 & 337 \\
& incorrect $d$ & 356 & 352 & 341 \\
& incorrect - correct & 25 & 37 & 4 \\
\hline
\end{tabular}

The results are similar to those of Experiment 1. There were main effects of speed $\left[F_{1}(34)=52.48, p<.01\right.$; $\left.F_{2}(38)=670.03, p<.01\right]$ and correctness $\left[F_{1}(34)=\right.$ $\left.21.48, p<.01 ; F_{2}(38)=12.88, p<.01\right]$ in both the participant and item analyses. Fast participants read faster than slow participants, and the sentences with correct verb forms elicited shorter reading times than did those with incorrect verb forms. Verb type was again only significant in the participant analysis $\left[F_{2}(34)=6.33, p=.02\right.$; $\left.F_{2}(38)=0.50, p>.10\right]$. We did not find a main effect of position in this experiment, but again there was an interaction of speed and position $\left[F_{1}(34)=12.72, p<.01\right.$; $\left.F_{2}(38)=23.07, p<.01\right]$, which confirmed that in this experiment as well, only slow readers needed more time to read the verb form (on average, $410 \mathrm{msec}$ ) than to read the following function word $(382 \mathrm{msec})$. Importantly, we also obtained the hypothesized interaction of verb type and correctness $\left[F_{1}(1,34)=12.70, p<.01 ; F_{2}(1,34)=\right.$ $4.88, p=.03]$. Correctness did not affect the reading of all sentences. If a $d$-supporting verb was misspelled, this misspelling did not affect the reading times $\left[F_{1}(1,34)=\right.$ $\left.2.63, p>.10 ; F_{2}(1,19)=1.42, p>.10\right]$. If, in contrast, neutral verbs were misspelled, the misspelling caused a significant delay $\left[F_{1}(1,34)=24.09, p<.01 ; F_{2}(1,19)=\right.$ $12.62, p<.01]$. We did not find any other interactions with correctness, unlike in Experiment 1, possibly because the effect of correctness was weaker on the neutral verbs than on the $t$-supporting verbs.

\section{Discussion}

Readers did not delay when a $d$-supporting verb was incorrectly spelled with $d$, whereas they were delayed significantly by a neutral verb incorrectly spelled with $d$. The neutral verbs and the $d$-supporting verbs in the experiment ended in highly comparable grapheme sequences, and the attested effect of verb type therefore cannot be due to the frequencies with which these sequences occurred with $d$ and $t$. The results form strong support for the hypothesis of intraparadigmatic effects in reading.

Theoretically, however, there is yet another possible account of the data. If the third-person singular present tense form of a $d$-supporting verb is spelled incorrectly with $d$, it is very similar to the corresponding simple-past form; the two forms only differ in that the simple past has an extra $e$ (see Tables 1 and 2). For instance, incorrect pleegd is very similar to the simple-past form pleegde. The misspelled forms of neutral verbs, on the contrary, are not similar to the corresponding simple-past forms, because those simple-past forms are irregular. Thus, incorrect weegd is not highly similar to woog. Possibly, readers had fewer problems with the misspelled forms of $d$-supporting verbs because they interpreted these misspelled forms as misspelled verbs in the simple past.

In Experiment 3, we tested whether the attested difference between $d$-supporting and neutral verbs is also present when the interpretation of the misspelled present tense forms as simple pasts is unlikely. Experiment 3 differed from Experiment 2 in two respects: First, the sentences started with an adverb. Sentences containing $d$-supporting verbs started with adverbs such as nu "now," tegenwoordig "nowadays," and morgen "tomorrow," which tend to occur in sentences in the present tense or the future and therefore introduce a bias against the interpretation of the verb form as a simple past. Second, the experiment included $20 t$-supporting verbs. These $t$-supporting verbs gave us the opportunity to replicate the results of Experiment 1 and also allowed us to investigate interparadigmatic analogy in reading. So far, we have focused on analogical effects induced by inflectionally related forms (intraparadigmatic analogy). As mentioned above, the reading of a verb form might also be affected by forms belonging to other verb paradigms that are phonologically or orthographically (henceforth, formally) similar. If so, the effect of an incorrect $d$ would be expected to be larger for the $t$-supporting verbs than for the neutral verbs in the experiment, since the neutral verbs are formally similar to $d$ supporting verbs and may receive support from these verbs for incorrect $d$. Hence, a difference between $t$-supporting verbs and neutral verbs may result from interparadigmatic effects in reading.

\section{EXPERIMENT 3}

\section{Method}

Participants. Forty native speakers of Dutch were paid for their participation. Most of them were undergraduate students at Radboud University Nijmegen. None of them had participated in Experiments 1 or 2 .

Materials and Design. We selected 20 monomorphemic $t$ supporting verbs in addition to the 20 monomorphemic $d$-supporting verbs and the 20 monomorphemic neutral verbs from Experiment 2 
(see the Appendix). The third-person singular present tense forms of these verbs are approximately of the same length [on average, 5.65, 5.20 , and 5.40 graphemes, respectively; for verb type, $F(2,57)=$ $2.57, p=.09$ ] and log frequency of occurrence [on average, 4.53 , 4.31 , and 4.58 ; for verb type, $F(2,57)=0.17, p>.10]$. We embedded the verb forms in sentences consisting of an adverb, the present tense verb form, a subject noun phrase of two words, and at least three more words (see Example 3). The adverbs in sentences with $d$-supporting verbs introduced a bias against interpreting the verb form as a simple past.

(3) Sentence: Morgenochtend reist mijn oma naar Portugal af. Tomorrow morning sets my grandmother for Portugal off. "Tomorrow morning my grandmother will set off for Portugal." Question: Heeft deze vrouw kleinkinderen?

"Does this woman have grandchildren?"

We constructed two experimental lists that were identical, except that the experimental items spelled incorrectly in one list were spelled correctly in the other list. Each list contained 10 incorrectly spelled forms of each verb type. The experimental items in a list were pseudorandomly mixed with 65 filler sentences. None of the filler sentences contained misspellings, so that Experiments 1-3 all contained approximately the same percentage of sentences with misspellings. Both lists were preceded by 14 practice sentences.

Procedure. The procedure was the same as in Experiments 1 and 2 .

\section{Results}

We included all participants in the data set, since they all answered more than $90 \%$ of the questions correctly. We excluded 355 reading times $(1.5 \%)$ that were more than two standard deviations away from both the participant and item means for a given position in a given condition. Table 7 shows the reading times for the correctly and incorrectly spelled verb forms, the following word, and the second following word. We analyzed the data by means of participant and item analyses of variance, with verb type ( $d$-supporting, $t$-supporting, neutral), correctness (correctly spelled vs. misspelled), position (the verb form itself, the immediately following word, or the second following word), and reading speed (the 20 fastest vs. the 20 slowest participants) as independent variables. We incorporated the second following word into these analyses because the means suggest that the spelling of the verb form did affect the reading time for this word (see Table 7). In contrast with the first two experiments, the second following word here was the subject of the sentence, so syntactic integration of the subject and the verb form took place at this position.

The results were similar to those of Experiments 1 and 2 . Both the participant and item analyses showed main effects of speed $\left[F_{1}(1,37)=58.13, p<.01 ; F_{2}(1,38)=\right.$ $1,878.12, p<.01]$ and correctness $\left[F_{1}(1,37)=62.58\right.$, $\left.p<.01 ; F_{2}(1,38)=18.21, p<.01\right]$. Fast participants read faster than slow participants, and all participants read sentences with correct verb forms faster than those with incorrect verb forms. The item analysis showed a main effect of position, which was only marginally significant in the participant analysis $\left[F_{1}(1,37)=2.98, p=\right.$ $\left..06 ; F_{2}(1,38)=8.48, p<.01\right]$. As in Experiments 1 and 2 , this main effect was modulated by an interaction of position and speed $\left[F_{1}(1,37)=4.94, p=.01 ; F_{2}(1,38)=\right.$ $19.96, p<.01]$, and as in Experiment 1, it was also modulated by an interaction of position and correctness $\left[F_{1}(1,37)=2.95, p=.07 ; F_{2}(1,38)=19.96, p=.02\right]$. In addition, we found an interaction of position, speed, and correctness $\left[F_{1}(1,37)=4.78, p=.01 ; F_{2}(1,38)=\right.$ $7.70, p<.01]$. Fast participants were especially delayed by an incorrect verb form when reading the two following words (averages at the three positions: $12 \mathrm{msec}, 44 \mathrm{msec}$, and $25 \mathrm{msec}$ ), but slow readers, in contrast, were especially delayed when reading the verb form itself $(44 \mathrm{msec}$, $17 \mathrm{msec}$, and $6 \mathrm{msec}$ ).

Also as in Experiments 1 and 2, verb type was significant in the participant analysis $\left[F_{1}(1,37)=15.73, p<\right.$ $\left..01 ; F_{2}(1,38)=0.91, p>.10\right]$, and its effect was once again modulated by the hypothesized interaction of correctness and verb type, which was highly significant in the participant analysis $\left[F_{1}(1,37)=14.64, p<.01\right]$ and marginally significant in the item analysis $\left[F_{2}(1,57)=\right.$ $2.87, p=.07]$. A separate analysis of the $d$-supporting verbs showed an effect of correctness in the participant analysis only $\left[F_{1}(1,38)=5.35, p=.03 ; F_{2}(1,19)=1.84\right.$, $p=.19]$. The neutral verbs showed an effect of correctness in both the participant and item analyses $\left[F_{1}(1,38)=\right.$ $\left.24.64, p<.01 ; F_{2}(1,19)=6.37, p=.02\right]$, and so did the $t$ supporting verbs $\left[F_{1}(1,38)=69.48, p<.01 ; F_{2}(1,19)=\right.$ $1.92, p<.01]$. Since the participant analysis showed a main effect of correctness for both the $d$-supporting verbs and the neutral verbs, we conducted an analysis only over

Table 7

Average Reading Times (in Milliseconds) for the Third-Person Singular

Present Tense Forms Correctly Spelled With $t$ or Incorrectly Spelled With $\boldsymbol{d}$ and for the Two Following Words in Experiment 3

\begin{tabular}{llrrr}
\hline & & $\begin{array}{c}\text { Verb } \\
\text { Form }\end{array}$ & $\begin{array}{c}\text { Following } \\
\text { Word }\end{array}$ & $\begin{array}{c}\text { 2nd Following } \\
\text { Word }\end{array}$ \\
\hline$d$-supporting verbs & correct $t$ & 354 & 337 & 347 \\
& incorrect $d$ & 375 & 345 & 347 \\
Neutral verbs & incorrect - correct & 21 & 8 & 0 \\
& correct $t$ & 356 & 330 & 344 \\
& incorrect $d$ & 370 & 360 & 358 \\
$t$-supporting verbs & incorrect - correct & 14 & 30 & 14 \\
& correct $t$ & 352 & 334 & 351 \\
& incorrect $d$ & 401 & 387 & 382 \\
& incorrect - correct & 49 & 53 & 31 \\
\hline
\end{tabular}


these two verb types in order to test for a difference. This analysis showed an interaction of verb type with correctness in the participant analysis $\left[F_{1}(1,35)=5.12, p=.03\right.$; $\left.F_{2}(1,38)=0.48, p>.10\right]$. Thus, as in Experiment 2, correctness had a smaller effect on the $d$-supporting verbs than on the neutral verbs. In order to investigate whether the effect of correctness was larger for the $t$-supporting verbs than for the neutral verbs, we also conducted an analysis over these two verb types only. This analysis showed that the interaction of correctness and verb type was significant in the participant analysis $\left[F_{1}(1,38)=\right.$ $\left.16.30, p<.01 ; F_{2}(1,38)=2.64, p>.10\right]$.

\section{Discussion}

Even though the misspelled forms of the $d$-supporting verbs were unlikely to be interpreted as simple pasts in this experiment, they did not delay reading. In contrast, the misspelled forms of the neutral verbs did. We thus conclude that intraparadigmatic support for $d$ facilitates the comprehension of incorrect $d$ and that intraparadigmatic analogy affects reading.

The interaction of correctness with verb type in the participant analysis over $t$-supporting verbs and neutral verbs suggests that an incorrect $d$ has a larger effect on $t$ supporting verbs than on neutral verbs. Neither the $t$ supporting verbs nor the neutral verbs support the incorrect $d$. The correct $t$, in contrast, is supported by the paradigms of the $t$-supporting verbs, whereas it is not supported by those of the neutral verbs. In consequence, a grapheme different from $t$ may lead to longer delays for $t$-supporting verbs than for neutral verbs. In other words, the difference between the two verb types may result from intraparadigmatic analogy. In addition, it may result from interparadigmatic analogy: Reading a verb form may activate the withinparadigm neighbors as well as the formal neighbors, which support $d$ in the case of neutral verbs. Finally, the difference between the $t$-supporting and the neutral verbs may result from the frequencies with which the final grapheme sequences of their stems are followed by $d$.

In Experiment 4, we further investigated the possibility that the reading of a verb form may be affected by interparadigmatic analogy. This self-paced reading experiment took as its point of departure the findings of Ernestus and Baayen $(2003,2004)$ already mentioned in the introduction. In Dutch, simple pasts are created by adding -te to the verb stem if the stem ends in an unvoiced obstruent before infinitival -en or any other vowel-initial suffix. Otherwise, the simple-past suffix is - $d e$. Thus, the realization of the stem-final obstruent before the infinitive suffix is the relevant feature, since the obstruent's realization in coda position is completely regulated in Dutch by phonological processes (final devoicing and regressive voice assimilation). Ernestus and Baayen found that speakers of Dutch base their choice between the simple-past allomorphs -de and -te not only on the realization of the final obstruent of the verb itself, but also on the gangs of phonological neighbors. Speakers tend to choose -te if the majority of the phonological neighbors end in unvoiced obstruents before vowel-initial suffixes, and they tend to choose - de if the majority end in voiced obstruents before such suffixes. The relevant gangs of neighbors are those represented in Table 3.

In Experiment 4, participants read sentences that featured regular simple pasts. These verb forms had either the simple-past allomorph that is prescribed by Dutch spelling conventions or the incorrect allomorph. For instance, the simple past of the verb schrobben, with a $b$ in the infinitive, was spelled correctly as schrobde or incorrectly as schrobte. Similarly, the simple past of stoppen, with a $p$, was spelled correctly as stopte or incorrectly as stopde. Note that speakers generally do know the correct spelling of the infinitive forms (schrobben vs. stoppen), and they are therefore able to determine the correct past tense forms.

If reading is affected by the phonological gangs defined by Ernestus and Baayen (2003), we would expect the incorrect allomorph to delay readers less when it is supported by the phonological gang of the verb. The verbs schrobben and stoppen activate the same phonological neighbors, because the verb stems schrob and stop in isolation end in the same phonological rhyme [op]. The fact that the stem-final obstruents differ in voicing in the infinitive, as is reflected in the spelling of the verb forms, is irrelevant for the activation of a gang. The verbs both activate the phonological gang of words ending in a short vowel and a bilabial plosive. This gang favors an unvoiced realization for the final obstruent before vowel-initial suffixes (the support for voicing is .135; see Table 3), and it consequently supports the allomorph -te, which typically follows obstruents that are unvoiced in the infinitive. Hence, we would expect that readers have more difficulty with incorrect stopde than with incorrect schrobte.

In the discussion that follows, we will refer to verbs for which the correct simple-past allomorph is supported by the phonological gang as lexically congruent. Verbs for which the correct allomorph is not supported by the phonological gang will thus be lexically incongruent. The verb stop, which has the simple past stopte, is lexically congruent, and schrob, with the simple past schrobde, is lexically incongruent.

\section{EXPERIMENT 4}

\section{Method}

Participants. Fifty-two native speakers of Dutch were paid to participate in the experiment. Most of them were undergraduate students at Radboud University Nijmegen. They had not participated in Experiments 1, 2, or 3 or in Ernestus and Baayen's $(2001,2004)$ simple-past production experiments.

Materials and Design. We selected 14 lexically congruent and 14 lexically incongruent monomorphemic verbs (see the Appendix). Their third-person singular simple-past forms were of approximately the same length [on average, 6.54 and 6.43 graphemes, respectively; $t(26)=0.16, p>.10$ ] and $\log$ frequency [on average, 4.14 and 4.03, respectively; $t(26)=0.22, p>.10]$. We embedded these verb forms in sentences consisting of a subject noun phrase of two words, the simple-past form, and at least two other words. The word following the verb form was either a function word or an adverb (whereas it 
was always a function word in Experiments 1, 2, 3, and 5). The sentences with lexically congruent simple pasts had the same syntactic structure as the sentences with lexically incongruent simple pasts. Each sentence was followed by a question (see Example 4).

(4) Sentence: Deze muur grensde vroeger aan een kleine speeltuin. This wall bordered previously on a small playground. "This wall used to border on a small playground." Question: Is de speeltuin verdwenen?

"Has the playground disappeared?"

We constructed two experimental lists that were identical, except that experimental items spelled with the correct simple-past allomorph in one list were spelled with the incorrect simple-past allomorph in the other, and vice versa. Note that the form of the suffix provided no information on the correctness of the verb form, since both the correct and incorrect forms could end in -de or -te.

Each list contained 14 simple pasts with incorrect allomorphs: 7 lexically congruent and 7 lexically incongruent. The 28 experimental sentences in each list were pseudorandomly mixed with 40 filler sentences. The filler sentences did not contain misspellings, because we expected that most participants would miss the misspellings in the experimental sentences; including obvious misspellings in the filler sentences would have drawn the readers' attention to spelling.

Procedure. The procedure was the same as in Experiments 1-3, except that the participants did not get the information that some sentences contained misspellings.

\section{Results}

We excluded 109 reading times that were more than two standard deviations away from both the participant and item means for a given position in a given condition $(0.8 \%)$. Table 8 presents the resulting average reading times for the simple-past forms and for the two directly following words, broken down by verb type (lexically congruent vs. incongruent) and correctness. We analyzed the data by means of participant and item analyses of variance, with the independent variables verb type (lexically congruent vs. incongruent), correctness (correct vs. incorrect simple-past allomorph), position (the simple-past form itself vs. the following word), and reading speed (the 26 fastest vs. the 26 slowest readers). We did not include the second word following the verb because the means suggest that the effect of correctness at this word is small and independent of verb type. If there are interparadigmatic effects on reading, we would expect an interaction of correctness with verb type.

We found main effects of speed $\left[F_{1}(1,50)=98.38\right.$, $\left.p<.01 ; F_{2}(1,26)=583.37, p<.01\right]$ and correctness $\left[F_{1}(1,50)=8.19, p<.01 ; F_{2}(1,26)=11.18, p<.01\right]$.
Fast readers were faster than slow readers, and readers needed more time to read sentences with incorrect than with correct forms. The effect of correctness was modulated by an interaction of correctness and position, which was significant in the item analysis $\left[F_{2}(1,26)=5.92, p=\right.$ $.02]$ and marginally significant in the participant analysis $\left[F_{1}(1,50)=3.55, p=.07\right]$. Readers were slowed by an incorrect spelling, especially when reading the directly following word (see Table 8).

Verb type was significant in the participant analysis only $\left[F_{1}(1,50)=25.80, p<.01 ; F_{2}(1,26)=1.74, p>\right.$ $.10]$. Importantly, the hypothesized interaction of correctness with verb type was significant $\left[F_{1}(1,50)=6.20\right.$, $\left.p=.02 ; F_{2}(1,26)=4.43, p=.05\right]$. Correctness affected the reading of the lexically congruent verbs $\left[F_{1}(1,50)=\right.$ $\left.10.65, p<.01 ; F_{2}(1,13)=11.22, p<.01\right]$, whose correct allomorph was supported by the formal neighbors. In contrast, correctness had no main effect on the lexically incongruent verbs $\left[F_{1}(1,50)=0.34, p>.10 ; F_{2}(1,13)=\right.$ $1.14, p>.10]$.

The data (see Table 8) suggest that there is an interaction of verb type, correctness, and position, but this interaction did not emerge as significant in the analyses. We tested the congruent and incongruent verbs separately for an interaction of position and correctness. This interaction was not significant for the congruent verbs $\left[F_{1}(1,50)<\right.$ $\left.1 ; F_{2}(1,13)=1.13, p>.10\right]$, whereas it was significant for the incongruent verbs $\left[F_{1}(1,50)=7.02, p=.01\right.$; $\left.F_{2}(1,13)=10.32, p<.01\right]$. For incongruent verbs, correctness did not affect the reading of the verb form itself $\left[F_{1}(1,50)=1.42, p>.10 ; F_{2}(1,13)=1.03, p>.10\right]$, but it did affect the reading of the following word $\left[F_{1}(1,50)=\right.$ $\left.8.43, p<.01 ; F_{2}(1,13)=6.32, p=.03\right]$.

\section{Discussion}

Experiment 4 showed that readers have fewer problems reading an incorrect simple-past allomorph if this allomorph is supported by formal neighbors of the verb. We therefore conclude that interparadigmatic analogy does affect reading.

The reading of simple-past forms is probably affected by analogy because interparadigmatic effects are part and parcel of the comprehension process. In addition, interparadigmatic analogy may play a role because speakers of Dutch have not learned to base their choices between the two simple-past allomorphs on an explicit deterministic

Table 8

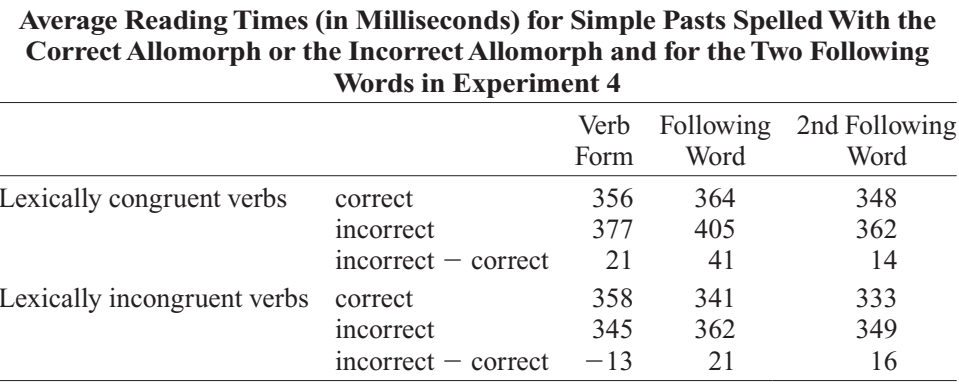


rule. They acquire both allomorphs from spoken language, and it is only later, when they are taught how to spell, that they learn explicitly the deterministic rule on which the choice of a simple-past allomorph may be based.

In Experiment 5, we tested whether analogical effects also emerge in reading if speakers have explicitly learned from the beginning to base their choice between allomorphs on a deterministic rule. We investigated the reading of Dutch regular past participles, which are created by prefixing the verb stem with [yə] (ge-) and suffixing it with [t] (see Tables 1 and 2). According to Dutch spelling conventions, the suffix $[\mathrm{t}]$ is spelled $-t$ after obstruents that are unvoiced in the infinitive ( $t$-supporting verbs) and $-d$ after all other segments ( $d$-supporting verbs). Since the suffix is not spelled in accordance with its pronunciation, language users might rely more on the deterministic rule that they learned at school for past participles than they did for simple pasts. If this is indeed the case, interparadigmatic analogical effects might not appear in the processing of past participles. However, language users might determine the past participle suffix in analogy with the simple past tense, a practice that is encouraged at some primary schools. Since there are analogical effects in the production of simple-past forms (Ernestus \& Baayen, 2004), in consequence, we may observe interparadigmatic effects in the reading of past participles as well. Finally, language users might process past participle suffixes by interparadigmatic analogy - that is, by activating the formal neighbors, which support one of the two allomorphs.

\section{EXPERIMENT 5}

\section{Method}

Participants. Eighty-two native speakers of Dutch who had not participated in Experiments 1, 2, 3, or 4 or in Ernestus and Baayen's (2001,2004) simple-past production experiments were paid for their participation. Most of them were undergraduate students at Radboud University Nijmegen.

Materials and Design. We selected regular past participles of 16 lexically incongruent and 16 lexically congruent monomorphemic verbs (see the Appendix). For half of the lexically congruent and half of the lexically incongruent past participles, the correct allomorph was $t$. For the other half, the correct allomorph was $d$. The past participles of the lexically congruent and incongruent verbs were of a similar length [on average, 4.25 and 4.38 graphemes, respectively; $t(30)=0.38, p>.10]$ and $\log$ frequency [both 1.94 on average; $t(30)=0.01, p>.10]$. The past participles were embedded in sen- tences consisting of a subject noun phrase of two words, a form of the auxiliary verb hebben, an object noun phrase of two words, the past participle, and two preposition phrases of three words. Each sentence was followed by a question (see Example 5).

(5) Sentence: De kinderen hebben hun namen gekrast in de schutting rond de tuin.

The children have their names scratched in the fence around the garden.

"The children scratched their names in the fence around the garden."

Question: Konden de kinderen toen al schrijven?

"Did the children by then know how to write?"

We constructed two experimental lists that were identical, except that the experimental items spelled incorrectly in one list were spelled correctly in the other. The two lists contained the same number of misspelled past participles of each kind (congruent with $t$, congruent with $d$, incongruent with $t$, incongruent with $d$ ). The 32 experimental sentences in each list were pseudorandomly mixed with 40 filler sentences, which did not contain misspellings. Both lists were preceded by the same 14 practice sentences.

Procedure. The procedure was the same as in Experiment 4.

\section{Results}

We excluded 386 reading times (1.2\%) that were more than two standard deviations away from both the participant and item means for a given position in a given condition. Table 9 presents the resulting average reading times for the past participles spelled with the correct and incorrect allomorphs and for the two following words. We analyzed the data by means of analyses of variance with the independent variables verb type (lexically congruent vs. incongruent), correctness (correct vs. incorrect allomorph), position (the past participle itself vs. the following word), and reading speed (the 41 fastest vs. the 41 slowest readers). Again, we disregarded the second word following the verb form, since the mean reading times for this word seemed unaffected by correctness.

Speed $\left[F_{1}(1,80)=140.03, p<.01 ; F_{2}(1.30)=681.88\right.$, $p<.01]$ and the interactions of speed with position $\left[F_{1}(1,80)=14.23, p<.01 ; F_{2}(1,30)=33.74, p<.01\right]$ and verb type with position $\left[F_{1}(1,80)=13.24, p<.01\right.$; $\left.F_{2}(1,30)=4.12, p=.05\right]$ emerged as significant in both the participant and item analyses. In general, fast readers needed less time than did slow readers, and although the fast readers needed less time to read the verb form (on average, $281 \mathrm{msec}$ ) than to read the following word (307 $\mathrm{msec})$, this trend was reversed for the slow readers (488 $\mathrm{msec}$ and $451 \mathrm{msec}$, respectively). All participants

Table 9

Average Reading Times (in Milliseconds) for Past Participles Spelled With the Correct Allomorph or the Incorrect Allomorph and for the Two Following Words in Experiment 5

\begin{tabular}{llrcc}
\hline & & $\begin{array}{c}\text { Verb } \\
\text { Form }\end{array}$ & $\begin{array}{r}\text { Following } \\
\text { Word }\end{array}$ & $\begin{array}{c}\text { 2nd Following } \\
\text { Word }\end{array}$ \\
\hline Lexically congruent verbs & correct & 388 & 386 & 324 \\
& incorrect & 386 & 403 & 329 \\
& incorrect - correct & -2 & 17 & 5 \\
Lexically incongruent verbs & correct & 392 & 361 & 318 \\
& incorrect & 373 & 365 & 320 \\
& incorrect - correct & -19 & 4 & 2 \\
\hline
\end{tabular}


read the following word faster if the verb was lexically incongruent (see Table 9).

There was also an interaction of position and correctness, although it was marginal in the participant analysis $\left[F_{1}(1,80)=3.31, p=.07 ; F_{2}(1,30)=11.18, p<.01\right]$, and an interaction of position, correctness, and speed $\left[F_{1}(1,80)=2.39, p>.10 ; F_{2}(1,30)=5.25, p=.03\right]$. The verb form itself showed no interaction of correctness with speed $\left[F_{1}(1,80)<1 ; F_{2}(1,30)<1\right]$, but the following word did $\left[F_{1}(1,80)=5.04, p=.03 ; F_{2}(1,30)=4.01\right.$, $p=.05]$ : Whereas fast readers were hardly affected by correctness while reading the following word (an incorrect spelling speeded them up by $8 \mathrm{msec}$ on average), the slow readers were delayed by an incorrect spelling by $51 \mathrm{msec}$ on average.

The participant analysis showed a main effect of verb type $\left[F_{1}(1,80)=20.98, p<.01 ; F_{2}(1,30)=1.16, p>\right.$ .10] that was modulated by the hypothesized interaction of verb type and correctness $\left[F_{1}(1,80)=4.90, p=.03\right.$; $\left.F_{2}(1,30)=1.25, p>.10\right]$. Given this interaction in the participant analysis, we analyzed the sentences with lexically congruent and incongruent verbs separately. The lexically incongruent verbs showed an interaction of correctness and position in the item analysis $\left[F_{1}(1,80)=\right.$ $\left.3.04, p=.09 ; F_{2}(1,15)=10.48, p<.01\right]$. Correctness did not affect the reading of the word directly following the past participle $\left[F_{1}(1,80)=0.43, p>.10 ; F_{2}(1,15)=\right.$ $0.83, p>.10]$, but it did affect the reading of the past participle itself $\left[F_{1}(1,80)=4.03, p=.05 ; F_{2}(1,15)=\right.$ $4.15, p=.06]$. Participants actually read faster when the past participle of a lexically incongruent verb was spelled with the incorrect allomorph than when it was spelled with the correct allomorph. In other words, the incorrect allomorph accelerated the reading of the lexically incongruent verbs.

The sentences with lexically congruent verbs mirrored the interaction of position, correctness, and reading speed from the overall analysis $[F(1,80)=3.38, p=.07$; $\left.F_{2}(1,15)=3.65, p=.08\right]$. Participants were not affected by the correctness of the allomorph when they read the past participles themselves $\left[F_{1}(1,80)=0.07, p>.10\right.$; $\left.F_{2}(1,15)=0.20, p>.10\right]$. When reading the following word, slow readers were affected by the spelling [interaction of correctness and reading speed, $F_{1}(1,80)=6.48$, $p=.01 ; F_{2}(1,15)=4.06, p=.06$; correctness for slow readers only, $F_{1}(1,40)=5.95, p=.02 ; F_{2}(1,15)=7.99$, $p=.01]$; they read the words following the past participles faster when the past participles were spelled correctly. Fast readers were not affected by correctness $\left[F_{1}(1,40)=\right.$ $\left.5.95, p>.10 ; F_{2}(1,15)=0.15, p>.10\right]$.

\section{Discussion}

The data suggest that an incorrect allomorph of the past participle suffix accelerates reading when it is supported by the formal neighbors of the verb. When it is not supported, it delays slow readers. This finding is in line with the hypothesis that interparadigmatic analogy affects reading.
It is not surprising that slow readers in particular suffer from an incorrect allomorph on the past participles of lexically congruent verbs. Slow readers may read more carefully than fast readers, and in consequence they may notice the correctness of the allomorph.

In the item analysis, the interaction of verb type and correctness was not significant. A possible reason for this is that verb type may be relevant only for the incorrect allomorph $d$. Slow readers were delayed $62 \mathrm{msec}$ on the word following a lexically congruent past participle with incorrect $d$ [their average reading time for the following word was $461 \mathrm{msec}$ when the verb form was correct and $523 \mathrm{msec}$ when it was incorrect; for correctness, $\left.F_{1}(1,40)=6.04, p=.02 ; F_{2}(1,7)=7.52, p=.03\right]$, but they were delayed less $(19 \mathrm{msec})$ on the word following a lexically congruent past participle with incorrect $t$ [the average reading time for the following word was $445 \mathrm{msec}$ when the verb form was correct and $464 \mathrm{msec}$ when it was incorrect; for correctness, $F_{1}(1,40)=1.02, p>.10$; $\left.F_{2}(1,7)=1.54, p>.10\right]$. A possible explanation for this difference between incorrect $d$ and $t$ is that past participles are always realized with [t] , and readers may only delay when the incorrect allomorph deviates from the pronunciation of the suffix. Analyses of variance including the shape of the correct allomorph (-t or $-d$ ) as a factor should reveal the difference between $t$ and $d$. If our explanation is correct, it should yield a four-way interaction of correctness, verb type, reading speed, and allomorph shape. We did not carry out this analysis, however, since the data set was too small to provide evidence for four-way interactions. We could not enlarge the data set, since the set of Dutch monomorphemic lexically incongruent verbs is highly restricted.

We tentatively conclude that the phonological gangs defined in Ernestus and Baayen (2003) also affect the reading of incorrect past participles. This suggests that interparadigmatic effects also arise when the pronunciation of the verb form does not provide information on the spelling of the suffix.

\section{GENERAL DISCUSSION}

This study investigated the role of intra- and interparadigmatic analogy in the reading of Dutch inflectional forms. In three self-paced reading experiments, present tense forms were either spelled correctly with the suffix $-t$ or misspelled with the suffix $-d$. All three experiments show that an incorrect $d$ causes longer delays when the verb does not take simple-past or past participle suffixes with $d$ or [d]. We conclude that the reading of a verb form is affected by the formal characteristics of the within-paradigm neighbors (intraparadigmatic analogy). In Experiments 4 and 5, participants read simple pasts and past participles. According to the spelling conventions of Dutch, these forms should be spelled with a suffix containing either $d$ or $t$, depending on the phonological characteristics of the stem. Participants read the forms with either the correct or the incorrect allomorph, given the phonological 
shape of the stem. The results, especially from the simplepast experiment, show that an incorrect allomorph causes shorter delays if there are more formally similar stems for which the allomorph is appropriate than for which it is inappropriate. We conclude that both intra- and interparadigmatic analogy affect the reading of inflected verb forms in Dutch. These analogical effects arose even though the words were presented in meaningful linguistic contexts, which suggests that the analogical effects are part and parcel of the comprehension process.

Dutch has an almost perfect one-to-one relation between sound and grapheme (the phonological principle). Word-final $d$, which is realized as [t], is one of the systematic exceptions. Given this nearly perfect one-to-one relation, we may expect that the more an incorrect spelling deviates from the pronunciation of the word, the more Dutch readers may have problems processing this spelling. The misspelling of the suffix $[\mathrm{t}]$ as $-d$ investigated in Experiments 1-3 violates the phonological principle, whereas the correct spelling - $t$ does not. Nevertheless, the incorrect $-d$ did not increase the reading times when it was supported by the within-paradigm neighbors of the verb form. In Experiment 5, the incorrect allomorph $-d$ also violated the phonological principle. Here we found that when this incorrect allomorph received support from the formal neighbors, the reading times were even shorter for this incorrect allomorph than for the correct allomorph, $-t$. We conclude that the analogical effects are so large that readers are not delayed by analogically supported incorrect spellings and allomorphs, even when these incorrect forms violate the phonological principle.

So far, we have left as an open question the extent to which orthographic similarity drives the analogical effects that we report in this article. In Experiments 4 and 5 , we determined the interparadigmatic support for an allomorph on the basis of the phonological neighbors. Since the relation between sound and grapheme is almost perfectly one to one in Dutch, the question arises whether it is indeed phonological similarity that drove the attested analogical effects in these experiments, or whether it was orthographic similarity instead. Words that are phonological neighbors may differ in the spelling of their final obstruents ( $b$ vs. $p, d$ vs. $t$, or $g$ vs. $c h$ ), but we nevertheless found that they do affect each other's reading times. That is, words are affected by words that end in similar sounds but not necessarily in similar graphemes. This finding strongly suggests that phonological similarity drives the analogical effects in reading at least partly.

There may be two different sources for the analogical effects in reading that are documented in this article. First, they may be due to online processes: The reading of a verb form activates the representation of this verb form in the speaker's lexicon, if present, as well as the representations for its stem, the within-paradigm neighbors, and the interparadigmatic neighbors. These activated representations may support the given spelling of the form, which may in turn shorten reading times. Second, the documented effects may be due to the possible storage of incorrect forms that result from analogy in production. Using the search engine AltaVista, we conducted a search on the Internet for the correct and incorrect forms used in Experiments 4 and 5. This research revealed that the lexically incongruent verbs are spelled with an incorrect allomorph much more frequently than are the lexically congruent verbs. The simple-past forms of the lexically incongruent verbs in Experiment 4 were spelled with an incorrect allomorph in $13 \%$ of cases, the congruent forms in less than $1 \%$ of cases. Similarly, the lexically incongruent past participles in Experiment 5 were spelled with an incorrect allomorph in $16 \%$ of cases, but the congruent past participles were spelled incorrectly in only $5 \%$ of cases. If a speaker stores nearly all frequently occurring word forms, the incorrect forms that are supported by analogy may especially leave traces. Speakers may consequently read these forms faster than the infrequent incorrect forms that are not supported by analogy and that they have not stored. Further research is necessary in order to determine the relative contributions of online processes and storage to analogical effects in reading.

In conclusion, previous studies (see, e.g., Ernestus \& Baayen, 2003, 2004; Krott, 2001; Krott et al., 2001; Skousen, 1989) have shown that the production of existing words and the creation of new morphologically complex forms in isolation are affected by the properties of semantic, phonological, morphological, and orthographical neighbors. Our results show that reading morphologically complex words in meaningful contexts is also affected by a word's lexical neighbors, and that these analogical effects are both intra- and interparadigmatic in nature.

\section{REFERENCES}

Alegre, M., \& Gordon, P. (1999). Frequency effects and the representational status of regular inflections. Journal of Memory \& Language, 40, 41-61.

BaAyen, R. H., Dijkstra, T., \& Schreuder, R. (1997). Singulars and plurals in Dutch: Evidence for a parallel dual-route model. Journal of Memory \& Language, 37, 94-117.

BaAyen, R. H., McQueen, J., DiJkstra, T., \& Schreuder, R. (2003). Frequency effects in regular inflectional morphology: Revisiting Dutch plurals. In R. H. Baayen \& R. Schreuder (Eds.), Morphological structure in language processing (pp. 355-390). Berlin: Mouton de Gruyter.

BaAyen, R. H., Piepenbrock, R., \& Gulikers, L. (1995). The CELEX lexical database [CD-ROM]. Philadelphia: University of Pennsylvania, Linguistic Data Consortium.

Breiman, L., Friedman, J. H., Olshen, R., \& Stone, C. J. (1984). Classification and regression trees. Belmont, CA: Wadsworth International Group.

BybeE, J. (2000). The phonology of the lexicon: Evidence from lexical diffusion. In M. Barlow \& S. Kemmer (Eds.), Usage-based models of language (pp. 65-85). Stanford: CSLI.

Ernestus, M., \& BaAyen, R. H. (2001). Choosing between the Dutch past-tense suffixes -te and -de. In T. van der Wouden \& H. de Hoop (Eds.), Linguistics in the Netherlands 2001 (pp. 81-93). Amsterdam: Benjamins.

Ernestus, M., \& BaAyen, R. H. (2003). Predicting the unpredictable: Interpreting neutralized segments in Dutch. Language, 79, 5-38.

ERnESTUS, M., \& BAAYEN, [R.] H. (2004). Analogical effects in regular past tense production in Dutch. Linguistics, 42, 873-903.

Frisson, S., \& SANDRA, D. (2002). Homophonic forms of regularly inflected verbs have their own orthographic representations: A developmental perspective on spelling errors. Brain \& Language, 81, 545-554. 
Just, M. A., Carpenter, P. A., \& Woolley, J. D. (1982). Paradigms and processes in reading comprehension. Journal of Experimental Psychology: General, 111, 228-238.

Krott, A. (2001). Analogy in morphology: The selection of linking elements in Dutch compounds. Unpublished doctoral dissertation, Radboud University Nijmegen.

Krott, A., BaAyen, R. H., \& Schreuder, R. (2001). Analogy in morphology: Modeling the choice of linking morphemes in Dutch. Linguistics, 39, 51-93.

Pisoni, D. B., Nusbaum, H. C., Luce, P. A., \& Slowiaczek, L. M. (1985). Speech perception, word recognition and the structure of the lexicon. Speech Communication, 4, 75-95.

SANDRA, D., Frisson, S., \& DAEMS, F. (1999). Why simple verb forms can be so difficult to spell: The influence of homophone frequency and distance in Dutch. Brain \& Language, 68, 277-283.

Schreuder, R., \& BAAYEN, R. H. (1997). How complex simple words can be. Journal of Memory \& Language, 37, 118-139.

Skousen, R. (1989). Analogical modeling of language. Dordrecht: Kluwer.

Stemberger, J. P., \& MacWhinney, B. (1986). Frequency and the lexical storage of regularly inflected forms. Memory \& Cognition, 14, 17-26.

Stemberger, J. P., \& MacWhinney, B. (1988). Are lexical forms stored in the lexicon? In M. Hammond \& M. Noonan (Eds.), Theoretical morphology: Approaches in modern linguistics (pp. 101-116). London: Academic Press.

\section{APPENDIX}

Materials for Experiment 1 $t$-supporting verbs: klapt, stept, schopt, schimpt, danst, grist, blust, krast $d$-supporting verbs: plaagt, spuugt, vlagt, turft, bloost, loost, raast, peinst

Materials for Experiment 2

Neutral verbs: zuigt, weegt, liegt, buigt, vliegt, zwijgt, stijgt, bergt, geeft, snuift, wrijft, schuift, drijft, graaft, sterft, prijst, leest, blaast, pluist, kiest

$d$-supporting verbs: zaagt, pleegt, voegt, deugt, klaagt, droogt, legt, zorgt, leeft, zweeft, streeft, proeft, wuift, beeft, durft, reist, vreest, huist, graast, raast

Materials for Experiment 3

$t$-supporting verbs: stapt, knoopt, klopt, sleept, gaapt, stopt, hoopt, kraakt, merkt, raakt, kweekt, smeekt, bluft, sloft, straft, blaft, sist, krast, lost, mist

Neutral verbs: zuigt, weegt, liegt, buigt, vliegt, zwijgt, stijgt, bergt, geeft, snuift, wrijft, schuift, drijft, graaft, sterft, prijst, leest, blaast, pluist, kiest

$d$-supporting verbs: zaagt, pleegt, voegt, deugt, klaagt, droogt, legt, zorgt, leeft, zweeft, streeft, proeft, wuift, beeft, durft, reist, vreest, huist, graast, raast

Materials for Experiment 4

Lexically congruent verbs: dopte, stepte, schimpte, raapte, surfte, kraste, wiegde, deugde, spuugde, zeefde, peinsde, grijnsde, raasde, smoesde

Lexically incongruent verbs: juichte, kuchte, pochte, surfte, kruiste, loenste, krijste, dubde, krabde, schrobde, tobde, glansde, grensde, bonsde

Materials for Experiment 5

Lexically congruent verbs: gedopt, geklapt, geschimpt, gehapt, gekrast, gegrist, geslist, gesist, gespuugd, gevlagd, gedeugd, geturfd, geloosd, geraasd, gebloosd, gegrijnsd

Lexically incongruent verbs: gekucht, gepocht, gejuicht, gesurft, gekruist, geëist, gekrijst, geloenst, gebonsd, geglansd, geplensd, geplonsd, gedubd, gekrabd, geschrobd, getobd

(Manuscript received December 17, 2003;

revision accepted for publication November 4, 2004.) 